\title{
Diffuse large B cell lymphoma presenting with acute liver failure: a case report
}

\author{
Sofía Grille ${ }^{1}$, Matilde Boada ${ }^{1}$, Virginia Bove ${ }^{1}$, Daniel Leal ${ }^{1}$, Andreína Brugnini ${ }^{2}$, Natalia Trias ${ }^{2}$, \\ Natalia Maciel ${ }^{3}$, Daniela Lens ${ }^{2}$, Cecilia Guillermo ${ }^{1}$, Lilián Díaz ${ }^{1}$
}

1. Cátedra de Hematología, Hospital de Clínicas, Facultad de Medicina, Universidad de la República, Montevideo, Uruguay. 2. Laboratorio de Citometría y Biología Molecular, Departamento Básico de Medicina, Hospital de Clínicas, Facultad de Medicina, Universidad de la República, Montevideo, Uruguay. 3. Cátedra de Anatomía Patológica, Hospital de Clínicas, Facultad de Medicina, Universidad de la República, Montevideo, Uruguay.

Correspondence: Sofía Grille. Address: Cátedra de Hematología, Hospital de Clínicas, Facultad de Medicina, Universidad de la República, Montevideo, Uruguay. E-mail: sofiagrille@gmail.com

Received: January 24, 2015

Accepted: April 6, 2015

Online Published: April 15, 2015

DOI : $10.5430 /$ crcp.v2n3p53

URL: http://dx.doi.org/10.5430/crcp.v2n3p53

\section{Abstract}

Acute liver failure (ALF) is an uncommon disease, and between its etiologies, malignant infiltration is quite rare and it carries high mortality. When ALF due to malignant infiltration occurs, the hematological malignancies are the most common including: Hodgkin lymphoma, non-Hodgkin Lymphoma (NHL) and acute and chronic leukemias. Hematologic malignancies often involve the liver, the NHL that most often involved the liver is the diffuse large B cell lymphoma accounting for $51 \%$ of all B-NHL cases, but they rarely present as ALF, thus is not commonly taken into account as an etiology of liver failure and is likely underrecognized. Here, we describe an unusual case of a patient diagnosed with a diffuse large B cell lymphoma, who developed an acute liver failure due to lymphoma liver infiltration, after the first chemotherapy cycle, that was not diagnosed at the initial staging. Finally the patient turns unresponsive to chemotherapy and die. We emphasize the importance of the early diagnosis by liver biopsy and the early start of chemotherapy treatment as the only hope of remission.

\section{Key words}

Diffuse large B cell lymphoma, Extranodal, Acute liver failure

\section{I ntroduction}

Diffuse Large B Cell Lymphoma (DLBCL) represents the most common histological subtype of lymphoma, accounting for $25 \%$ of Non Hodgkin Lymphomas (NHL) in the world ${ }^{[1]}$. It includes a number of heterogeneous entities that can be defined separately according to de 2008 World Health Organization Classification ${ }^{[2]}$.

Extra nodal disease occurs in $40 \%$ of the cases being the gastrointestinal tract the most common site ${ }^{[3]}$. Liver is a common site for metastasis in all types of cancer and some series report that it is compromised in $36 \%$ of cancer related deaths. It is also frequently involved in NHL and can be compromised at initial staging ${ }^{[4]}$. 
Acute liver failure (ALF) is defined by the development of severe acute liver injury with encephalopathy, and evidence of coagulation abnormality (INR $>1.5$ ) with a disease duration less than 26 weeks in patients without cirrhosis or preexisting liver disease ${ }^{[5,6]}$. Untreated, the prognosis is poor, so timely recognition and management of patients with acute liver failure is essential. Identifying the underlying cause is crucial in both guiding treatment and predicting the outcome.

ALF due to malignant infiltration is rare. However, when it occurs the hematological malignancies are the most common causes including: Hodgkin lymphoma ${ }^{[7,8]}$ and NHL ${ }^{[9-12]}$, acute and chronic leukemia ${ }^{[13]}$ and malignant histiocytosis ${ }^{[14]}$. When NHLs present with ALF they have a very poor prognosis with a mortality rate over $90 \%{ }^{[15]}$.

We describe an unusual case of a patient at the University Hospital in Montevideo-Uruguay, diagnosed with DLBCL, who developed an acute liver failure due to lymphoma liver infiltration, after the first chemotherapy cycle, that was not diagnosed at the initial staging.

\section{Case presentation}

A 74 year-old women with a DLBCL diagnosed a month and a half ago was admitted in our hospital.

At presentation she had a stage IIIA DLBC NHL, IPI High intermediate-3 risk factor (older than 60 years, elevated lactate dehydrogenase, performance status of 1 , Ann Arbor stage III, without extranodal involvement). Computed tomography at presentation informed multiple lymphadenopathy involving neck, mediastinum, hepatic and splenic hilum and pelvis, splenomegaly ( 800 of splenic index), without liver enlargement. Cervical node biopsy was performed. Histology of lymph node showed atypical lymphoid proliferation of large cells with scant cytoplasm, high mitotic index and disposed in a diffuse pattern. The immunohistochemistry analysis showed that neoplastic cells were cytokeratin negative, CD10-, CD3, CD5-, CD30-, CD45+, CD20+ and BCL2+. Ki-67 was from 60\% to 70\%. These findings were consistent with DLBCL. Lymph node flow cytometry immunophenotype showed cells with elevated FSC/SSC with the following expression: CD45+, CD19+, CD20+, BCL2+, CD5-, CD10-, without light chains expression compatible with DLBCL. Bone marrow biopsy showed no involvement.

While she was being studied and staged, she began with abdominal pain, vomits, jaundice and dark urine. No fever or other infectious symptoms. She had no history of previous illness, any drugs or alcohol intake and was on no medications. Physical examination revealed universal jaundice, and cervical superficial lymphadenopathies. Laboratory findings showed: elevated white blood cells $\left(15.610 / \mathrm{mm}^{3}\right)$, deteriorated liver function, high Bilirubin $(7.97 \mathrm{mg} / \mathrm{gl})$ with predominance of direct Bilirubin $(7.27 \mathrm{mg} / \mathrm{dl})$, descended Albumin $(2.4 \mathrm{~g} / \mathrm{dl})$, increase of liver enzymes $(66 \mathrm{U} / \mathrm{L}$ ALT, $214 \mathrm{U} / \mathrm{L}$ AST, $740 \mathrm{U} / \mathrm{L}$ GGT), Alkaline Phosphatase (1,135 U/L) and Lactate Dehydrogenase (2,434 U/L), altered coagulation tests (61\% PT, > 100s APTT, INR 1.32). Serologic tests for primary hepatotropic viruses, Epstein-Barr virus and cytomegalovirus were negative. Abdominal ultrasound showed intrahepatic biliary duct dilatation and hepatic hilium lymphadenopathy, without evidence of gallstones. She was treated with chemotherapy, receiving only Cyclophosphamide and Prednisone, because of liver impairment which contraindicates doxorubicin and vincristine ${ }^{[16]}$. She had a good evolution with normal liver function in 72 hours and was discharged.

At day 18 post chemotherapy she was admitted at emergency service for 72 hours of jaundice, nausea and asthenia. She did not present either fever or infectious symptoms. On initial examination, she was oriented to person and place. The temperature was $36.5^{\circ} \mathrm{C}$, the blood pressure $120 / 70 \mathrm{mmHg}$, the pulse 120 beats per minute, the respiratory rate 18 breaths per minute, and the oxygen saturation was $99 \%$. The sclera was icteric; cervical superficial lymphadenopathies were palpable, the abdomen was tender without rigidity, and bowel sounds were present, and the remainder of the examination was reportedly normal. Laboratory findings showed metabolic acidosis $\left(\mathrm{pH} 7.3, \mathrm{HCO}_{3}-18.6 \mathrm{mmol} / \mathrm{L}\right)$ with elevated lactate $(11.7 \mathrm{mmol} / \mathrm{L})$, liver impairment with elevated bilirubin $(3.43 \mathrm{mg} / \mathrm{dl}$; with direct bilirubin predominance $2.32 \mathrm{mg} / \mathrm{dl}$ ), elevated alkaline phosphatase (2,422 U/L) and liver enzymes (AST $135 \mathrm{U} / \mathrm{L}$ and ALT $37 \mathrm{U} / \mathrm{L}$ ), and altered 
coagulation tests (PT 57\%, APTT $35 \mathrm{sec}$, INR 1.39 and fibrinogen $331 \mathrm{mg} / \mathrm{dl}$ ). Blood count showed anemia (hemoglobin $10.5 \mathrm{gr} / \mathrm{dl})$, elevated white blood cells $\left(23.800 / \mathrm{mm}^{3}\right)$ and thrombocytopenia $\left(63.000 / \mathrm{mm}^{3}\right)$. Abdomen ultrasound, computed tomography and magnetic resonance cholangiography showed diffuse enlarged liver without evidence of biliary duct dilatation or hepatic or portal-vein thrombosis (see Figure 1). Further laboratory investigations including hepatitis A, $\mathrm{B}$ and $\mathrm{C}$, Epstein-Barr virus, herpes simplex virus, cytomegalovirus, and human immunodeficiency virus serologies were normal. Blood and urine culture were sterile. The patient was admitted to intermediate care unit. She was treated with sulbactam-ampicilin, vitamin K, omeprazole and high dose corticosteroids. The patient initially became clinically stable and laboratory showed acidosis and lactate correction, improvement in liver function and coagulation tests. Some days later, the patient became increasingly confused with asterixis stage III encephalopathy ${ }^{[17]}$ and progressive jaundice. Laboratory findings showed progressive declining of liver function and coagulation test showed severe coagulopathy. She was treated with antibiotics, vitamin K, rifaximin, lactulose, omeprazole, intravenous fluids, platelet and fresh frozen plasma. Although the patient was not in opportunity to perform liver biopsy, with clinical diagnosis of acute liver failure due to liver lymphoma infiltration, empirical treatment was initiated with high dose corticosteroids and cyclophosphamide. There was no clinical improvement and the patient died five days later. The day before she died laboratory showed persistent metabolic acidosis with elevated lactate, liver impairment with elevated bilirubin (7.49 $\mathrm{mg} / \mathrm{dl}$; with direct bilirubin predominance $6.23 \mathrm{mg} / \mathrm{dl}$ ), elevated alkaline phosphatase $(1,140 \mathrm{U} / \mathrm{L}$ ) and liver enzymes (AST $61 \mathrm{U} / \mathrm{L}$ and ALT $11 \mathrm{U} / \mathrm{L}$ ), and the coagulation test were not coagulable. Blood count showed anemia (hemoglobin $7.1 \mathrm{gr} / \mathrm{dl})$ and thrombocytopenia $\left(22.000 / \mathrm{mm}^{3}\right)$.

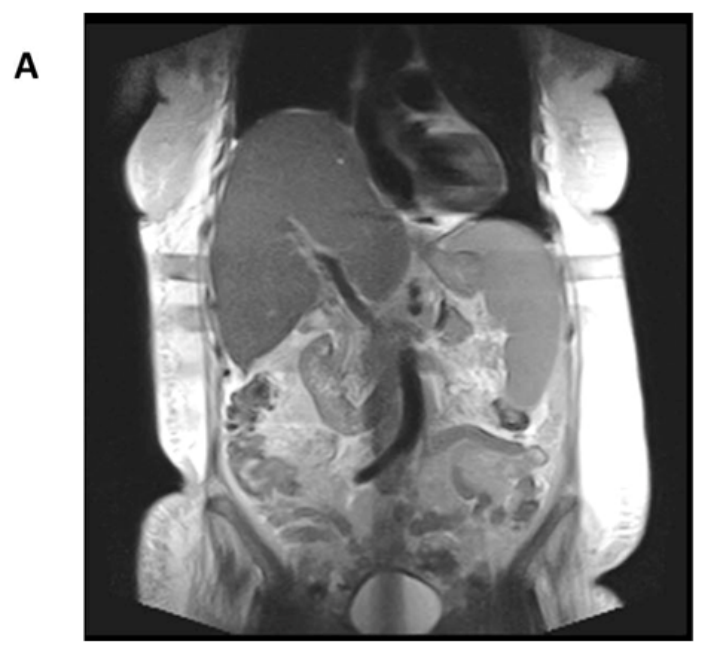

$$
\text { B }
$$

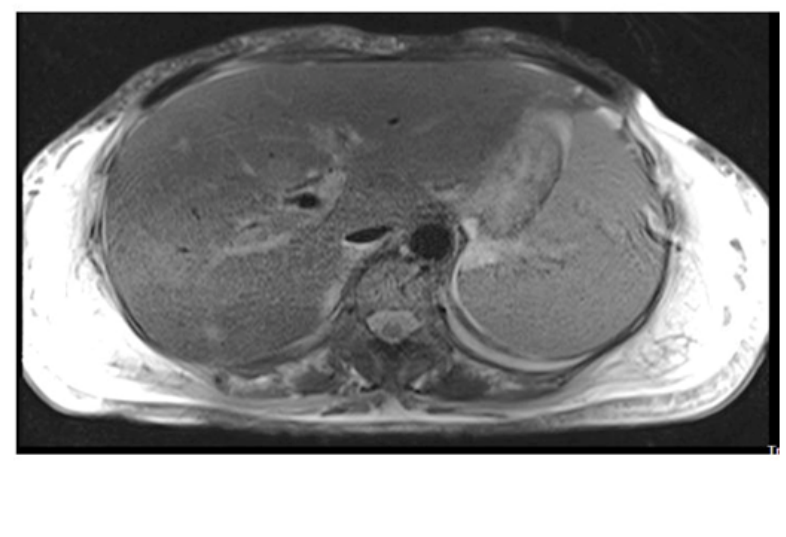

Figure 1. Nuclear magnetic resonance of the Abdomen and Pelvis. Coronal (panel A) and axial (panel B) image of the abdomen show diffuse enlarged liver.

Post mortem liver biopsy was performed and as shown in Figure 2, flow cytometry immunophenotype showed B lymphocytes with elevated FSC/SSC with the expression of CD45+, CD19+, CD20+, CD5- and CD 10-, without light chains expression compatible with DLBCL (similar to previous lymph node analysis). Hematopathology of liver biopsy showed liver parenchyma infiltration by medium sized cells with scant cytoplasm, vesicular nuclei similar to lymphoid cells, confirming liver infiltration by NHL (see Figure 3).

\section{Discussion}

The diagnosis of ALF is a medical emergency because its high mortality without liver transplantation ${ }^{[5,18]}$. The Intractable Hepato-biliary Diseases Study Group of Japan annually performs a nationwide survey of patients with ALF and late-onset ALF. The survival rates of non-liver-transplanted patients with ALF were $54 \%$ for acute, $24 \%$ for subacute and $15 \%$ for late-onset $\mathrm{ALF}^{[19]}$. 
Figure 2. Liver flow cytometry immunophenotype. Flow cytometry dots plot show NHL B cells (68\%, dark gray dots) with elevated FSC/SSC with the following phenotype: $\mathrm{CD} 19+, \mathrm{CD} 20+$, CD5- and without light chains expression. Normal B cells represent $0.6 \%$ (black dots) and normal $\mathrm{T}$ cells represent $30 \%$ (light gray dots). Lower left box plot shows CD19 fluorescence intensity with NHL B cells having lower levels of CD19 expression.
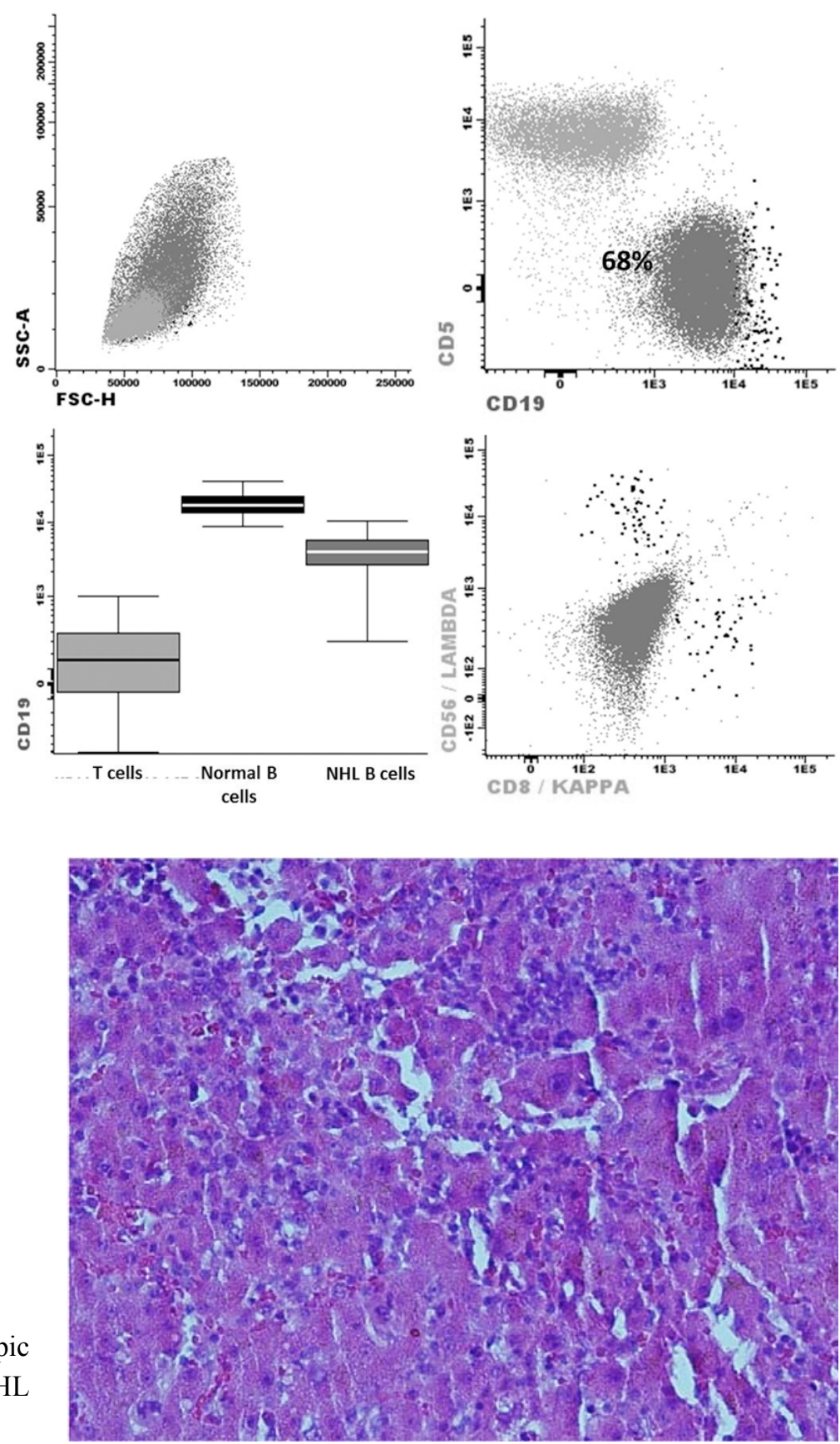

Figure 3. Pos-mortem liver biopsy. Microscopic assessment (hematoxylin and eosin) reveals NHL liver infiltration.

ALF can result from several etiologies, being viral, toxic and autoimmune hepatitis the most common ${ }^{[19]}$. ALF has been reported in patient with malignant infiltration of the liver due to hematological, lung, breast, melanoma and others cancers. Although hematologic malignancies (specifically lymphoma) often involve the liver (approximately 15\%), they uncommonly present as ALF ${ }^{[20]}$. Acute leukemias ${ }^{[20,21]}$, Hodgkin's disease ${ }^{[7,8]}, \mathrm{T}, \mathrm{B}$ and NK NHL ${ }^{[9-12,21,22]}$ and transformation of chronic leukemia ${ }^{[13]}$ have all been published in case reports or case series as they may present with ALF. All reported cases of ALF in hematological diseases occur at the time of presentation or at relapse of the disease. To the best of our knowledge, a case of disease progression after the first cycle of chemotherapy with ALF has not been described yet.

DLBCL is the most common histologic subtype of NHL accounting for approximately 25 percent of NHL cases ${ }^{[1,2]}$. Patients with DLBCL typically present with a rapidly enlarging mass, usually a nodal enlargement, systemic "B" 
symptoms are observed in approximately 30 percent of patients and the serum lactate dehydrogenase (LDH) is elevated in over one-half of them. Approximately 60 percent of patients will present with advanced stage DLBCL (usually stage III or IV disease) ${ }^{[23,24]}$. Extranodal involvement is common ${ }^{[25]}$ and extranodal extramedular disease occurs in up to 40 percent of cases ${ }^{[3]}$. The most common site of extranodal involvement is the gastrointestinal tract but the disease can arise in virtually any tissue, including the skin, salivary glands, tonsil, testis, bone, thyroid, liver, breast, paranasal sinuses, central nervous system and others ${ }^{[25]}$. The NHL that most often involved the liver is the DLBCL accounting for $51 \%$ of all B-NHL cases. Non-germinal center B-cell-like type is the DLBCL subtype that more frequently involve the liver. In the vast majority of cases hepatic involvement reflects secondary dissemination in advanced disease rather than a primary site $^{[26]}$.

Different mechanisms have been suggested to explain liver failure due to liver infiltration: tumor infiltration of the biliary tree, hepatic parenchyma and hepatic vasculature. Also hepatic parenchyma can be replaced by lymphoma cells with diffuse intrasinusoidal propagation and secondary hepatic ischemia ${ }^{[27]}$.

Clinical manifestations of ALF occur when hepatocytes become necrotic ${ }^{[20]}$ and in addition to hepatic encephalopathy, abnormal liver blood tests, and an INR $\geq 1.5$ (all of which are required for the diagnosis), it may include jaundice, hepatomegaly, right upper quadrant tenderness, thrombocytopenia and lactic acidosis being all present in our patient. Determining the etiology of ALF requires a combination of an adequate medical history, laboratory tests and imaging studies. If initial evaluations fail to identify an etiology, a liver biopsy may be required. The last remains the most valuable tool for diagnosis NHL liver infiltration. Transjugular or percutaneous liver biopsy can be used to obtain adequate tissue samples having both similar complications and mortality rates ${ }^{[28]}$. In our case, it was not possible to perform liver biopsy, so we proceeded to empiric chemotherapy treatment.

Survival in ALF is low despite the etiology. Most important factors for predicting the outcome in acute liver failure are: degree of encephalopathy, patient's age and the cause of the acute liver failure. ALF due to cancer infiltration is an adverse prognostic factor ${ }^{[29]}$. Despite the poor prognosis, chemotherapy treatment should be started as soon as possible. CHOP chemotherapy can be challenging with severe hepatic dysfunction and substantial dose reduction may be required ${ }^{[29]}$. Unless early diagnosis is made and chemotherapy rapidly introduced, fatal evolution is inevitable ${ }^{[15]}$. Even with early diagnosis and treatment introduction, the mortality rate is still around $90 \%{ }^{[29]}$. Lettieri et al. reported that chemotherapy has only been successful in inducing remission in 3 of 23 cases of NHL with ALF ${ }^{[12]}$.

In summary, this is a rare case of DLBCL with an ALF as manifestation due to liver infiltration. The diagnosis was made on post-mortem liver biopsy and treatment had no effect on stopping progression of the patient's disease who died several days after admission. We emphasize the importance of the early diagnosis by liver biopsy and the early start of chemotherapy treatment as the only hope of remission.

\section{Acknowledgements}

The authors thank all those who participated in diagnosis and treatment, specifically Internal Medicine Department and Radiology Department.

\section{References}

[1] Morton LM, Wang SS, Devesa SS, et al. Lymphoma incidence patterns by WHO subtype in the United States, 1992-2001. Blood. 2006; 107: 265-76. http://dx.doi.org/10.1182/blood-2005-06-2508

[2] Swerdlow SH, Campo E, Harris NL, et al. World Health Organization Classification of Tumours of Haematopoietic and Lymphoid Tissues. Lyon: IARC Press; 2008.

[3] Møller MB, Pedersen NT, Christensen BE. Diffuse large B-cell lymphoma: Clinical implications of extranodal versus nodal presentation - A population-based study of 1575 cases. Br J Haematol. 2004; 124: 151-9.

http://dx.doi.org/10.1046/j.1365-2141.2003.04749.x

Published by Sciedu Press 
[4] Chabner BA, Johnson RE, Young RC, et al. Sequential nonsurgical and surgical staging of non-Hodgkin's lymphoma. Ann Intern Med. 1976; 85: 149-54. PMid: 782309. http://dx.doi.org/10.7326/0003-4819-85-2-149

[5] Polson J, Lee WM. American Association for the Study of Liver Disease. AASLD position paper: the management of acute liver failure. Hepatology. 2005; 41: 1179-97. http://dx.doi.org/10.1002/hep.20703

[6] Lee WM, Stravitz RT, Larson AM. Introduction to the revised American Association for the Study of Liver Diseases Position Paper on acute liver failure 2011. Hepatology. 2012; 55: 965-7. http://dx.doi.org/10.1002/hep.25551

[7] Fairbank WHD. Hodgkin's Disease with Liver Damage. Can Med Assoc J. 1953; 69: 315-7. PMid: 13082480.

[8] Ortín X, Rodríguez-Luaces M, Bosch R, et al. Acute liver failure as the first manifestation of very late relapsing of Hodgkin's disease. Hematol Rep. 2010; 2: e5. http://dx.doi.org/10.4081/hr.2010.e5

[9] Ma Y-J, Chen E-Q, Chen X-B, et al. Primary hepatic diffuse large B cell lymphoma: A case report: Primary hepatic diffuse large B cell lymphoma. Hepat Mon. 2011; 11: 203-5. PMid: 22087145.

[10] Muñoz O, Villa P, Echeverri C, et al. Acute liver failure due to diffuse large B-cell lymphoma. Gastroenterol Hepatol. 2013; 36: 463-6. http://dx.doi.org/10.1016/j.gastrohep.2013.01.014

[11] Shetty S, Holt AP, Syn W-K, et al. Haematological malignancies presenting with acute liver injury: a single-centre experience. QJM. 2008; 101: 949-53. http://dx.doi.org/10.1093/qjmed/hcn121

[12] Lettieri CJ, Berg BW. Clinical features of non-Hodgkins lymphoma presenting with acute liver failure: a report of five cases and review of published experience. Am J Gastroenterol. 2003; 98: 1641-6. http://dx.doi.org/10.1111/j.1572-0241.2003.07536.x

[13] Greer JP, Cousar JB, Miller RF, et al. T4+ (helper phenotype) chronic lymphocytic leukemia: case report with liver failure and literature review. Med Pediatr Oncol. 1988; 16: 356-62. PMid: 2972899. http://dx.doi.org/10.1002/mpo.2950160514

[14] Colby TV, LaBrecque DR. Lymphoreticular malignancy presenting as fulminant hepatic disease. Gastroenterology. 1982; 82: 339-45. PMid: 7054034.

[15] Rowbotham D, Wendon J, Williams R. Acute liver failure secondary to hepatic infiltration: a single centre experience of 18 cases. Gut. 1998; 42: 576-80. PMid: 9616324. http://dx.doi.org/10.1136/gut.42.4.576

[16] Gordon LI, Harrington D, Andersen J, et al. Comparison of a second-generation combination chemotherapeutic regimen (m-BACOD) with a standard regimen (CHOP) for advanced diffuse non-Hodgkin's lymphoma. N Engl J Med. 1992; 327: 1342-9. http://dx.doi.org/10.1056/NEJM199211053271903

[17] Conn HO, Leevy CM, Vlahcevic ZR, et al. Comparison of lactulose and neomycin in the treatment of chronic portal-systemic encephalopathy. A double blind controlled trial. Gastroenterology. 1977; 72: 573-83. PMid: 14049.

[18] Murray KF, Carithers RLJ. AASLD practice guidelines: Evaluation of the patient for liver transplantation. Hepatology. 2005; 41: 1407-32. http://dx.doi.org/10.1002/hep.20704

[19] Oketani M, Ido A, Tsubouchi H. Changing etiologies and outcomes of acute liver failure: A perspective from Japan. J Gastroenterol Hepatol. 2011; 26 Suppl 1: 65-71. http://dx.doi.org/10.1111/j.1440-1746.2010.06574.x

[20] Myszor MF, Record CO. Primary and secondary malignant disease of the liver and fulminant hepatic failure. J Clin Gastroenterol. 1990; 12: 441-6. http://dx.doi.org/10.1097/00004836-199008000-00018

[21] Davis ML, Hashemi N. Acute liver failure as a rare initial manifestation of peripheral T-cell lymphoma. World J Hepatol. 2010; 2: 384-6. http://dx.doi.org/10.4254/wjh.v2.i10.384

[22] Dellon ES, Morris SR, Tang W, et al. Acute liver failure due to natural killer-like T-cell leukemia/lymphoma: a case report and review of the literature. World J Gastroenterol. 2006; 12: 4089-92. PMid: 16810767.

[23] Armitage JO, Weisenburger DD. New approach to classifying non-Hodgkin's lymphomas: clinical features of the major histologic subtypes. Non-Hodgkin's Lymphoma Classification Project. J Clin Oncol. 1998; 16: 2780-95. PMid: 9704731.

[24] A clinical evaluation of the International Lymphoma Study Group classification of non-Hodgkin's lymphoma. The Non-Hodgkin's Lymphoma Classification Project. Blood. 1997; 89: 3909-18. PMid: 9166827.

[25] Hui D, Proctor B, Donaldson J, et al. Prognostic implications of extranodal involvement in patients with diffuse large B-cell lymphoma treated with rituximab and cyclophosphamide, doxorubicin, vincristine, and prednisone. Leuk Lymphoma. 2010; 51: 1658-67. http://dx.doi.org/10.3109/10428194.2010.504872

[26] Loddenkemper C, Longerich T, Hummel M, et al. Frequency and diagnostic patterns of lymphomas in liver biopsies with respect to the WHO classification. Virchows Arch. 2007; 450: 493-502. http://dx.doi.org/10.1007/s00428-007-0384-9

[27] Bhat YM, Krasinskas A, Craig FE, et al. Acute liver failure as an initial manifestation of an infiltrative hematolymphoid malignancy. Dig Dis Sci. 2006; 51: 63-7. http://dx.doi.org/10.1007/s10620-006-3085-3

[28] Kalambokis G, Manousou P, Vibhakorn S, et al. Transjugular liver biopsy--indications, adequacy, quality of specimens, and complications--a systematic review. J Hepatol. 2007; 47: 284-94. http://dx.doi.org/10.1016/j.jhep.2007.05.001

[29] O'Grady JG, Alexander GJ, Hayllar KM, et al. Early indicators of prognosis in fulminant hepatic failure. Gastroenterology. 1989; 97: 439-45. PMid: 2490426. 